\title{
AWerner A2 ewer from Byzantine Cartagena and the distribution of bronze cast vessels in the western Mediterranean around 600 CE - ERRATUM
}

\author{
Joan Pinar Gil and Jaime Vizcaíno Sánchez
}

doi: $10.1017 / S 1047759421000556$

The authors' surnames were incorrectly tagged in the published version of this article by J. Pinar Gil and J. Vizcaíno Sánchez. The article XML has since been updated.

\section{Reference}

Pinar Gil, J., and J. Vizcaíno Sánchez. 2021. "A Werner A2 ewer from Byzantine Cartagena and the distribution of bronze cast vessels in the western Mediterranean around 600 CE." JRA. FirstView. https://doi.org/10.1017/S1047759421000556. 